\title{
The Unity of Scientific Literacy Education and Humanistic Spirit Education in Higher Education
}

\author{
Shixin Pei, Fenping Cui, Tingting Sun \\ College of Physics \& Opto-electronic Engineering, Nanjing University of Information Science \& Technology, \\ NUIST, Nanjing, China \\ Email: peishixin@nuist.edu.cn
}

Received 2012

\begin{abstract}
In view of the irrational phenomenon of many highly educated intellectuals showed non-rational behavior; it consider that the reason for this non-rational behavior is caused by the artificial fragmentation of scientific attainment education and humanistic spirit education in modern China higher education. This article maintains that healthy higher education should be based on scientific literacy, oriented by humanistic spirit, and to aim at the promotion of students personality perfection. Based on these, this paper ideal is the unity of human spirit education and science literacy education in modern Chinese colleges and universities is need urgently, that is to fully integrate the human spirit and science literacy, practice the way of the combination of science and humanities education. Focus on the combination, the connotations, objectives and ways to realize are disscussed in this paper, it is thinking that practices the combination of science and humanities education way should develop education theory, establish the educational methodology suitable for the science and humanities education, and seek the reuniting of science and humanities education from the history of science literacy education and humanities spirits education, reform the probleme in the combination of science education and humanities education, to carry out the education of science and humanities at the same time, reshaping the values of today higher education.
\end{abstract}

Keywords: Teaching Reform; Scientific Literacy Education; Humanistic Spirit Education; Science \& Humanities Education

\section{Introduction}

There is a true story widely quoted saying that a survivors from Nazi concentration camp after World War II became a school principal, whenever a new teacher came to the school, the principal would give the new teacher a letter: "dear teacher, I saw human beings should not to see the scene: Poison gas chambers were built by engineers with expertise; children were poisoned to death by the learned doctor; children were killed by trained nurses. When I see all this, I doubt: education, whether it is for what? My request is please help students grow as humane. Only our children grow up to be a really humane people, the ability of read, write and count have value. "

This true story, not only convey to us is awareness of the fundamental value of respect for life education, but also reveals the importance of the unity of natural sciences and human spirits in education. If education put aside the moral values, just talk about "knowledge", this "knowledge" is most likely to evolve into heresy, may become machinations, even nightmare.

Nightmare emerged continuously in recent years such as suicide, homicide, killing teacher, matricide ... some highly educated people and college students despise the human life and lack of life awarenesse should arouse people's alertness, this is not only the topic about respect life, take responsibility and improve the anti-frustration force[1], but also the distorted human nature caused by no humanistic spirit, which are closely

*This work was supported by the 7th \& 8th teaching building and reform project of NUIST (No.10KC012 \& No.11JY053). related to the long lack of humanistic spirit in higher education.

Einstein said that the core values of education is to let human nature to be improven, he believe that students could be a useful machine by professional education, but not necessarily to become a harmonious development man, to make students understand the value and produce warm feelings, obtain a clear cut discrimination of beauty and moral, therefore, it is not enough only professional knowledge education.

\section{Asymmetry of Science Literacy\&Humanistic Spirit Education for Modern College Students}

Human spirit reveal the meaning of human being existence, reflect the life value, it is cultural values of an era [2]; Science literacy is the knowledge and ability people should have to deal with the relationship with nature, that is people use scientific knowledge to deal with the problem [3].

\section{Fragmentation of Human Spirit and Science Literacy}

Before the mid-19th century, the fundamental purpose of universities was training physical and psychological developed people, the purpose of higher education is to search for truth and perfect personality, even Cambridge and Oxford, did not develop intellectuals, but train service personnel for the church or government.

With the development of science and technology, human spirit education in universities was challenged since the start of the industrialization, because human society need expertise who master science and technology urgently, the University's mis- 
sion shift to train technical personnel, science become an important part of university education, the function of science education gradually replaced the humanistic spirit education.

Universities in China established in the late 19th century and early 20th century, although the main motivation of the University's establishment is to make country rich and to build up military power, main content is to develop the natural science education, but retains part cultural education, especially traditional Chinese humanism education. To the 1950s, for one sided learning the Soviet Union, the faculties were adjusted across the country, the implementation of the humane and science separated education across the whole country, some universities which were focus on the development of science, even cancel humanities and social science departments, science and human spirit were artificially separated.

\section{Adverse Reactions of Human Spirit and Science Literacy were Artificially Fragmented}

Tsinghua University professor Peng Lin pointed out that the phenomenon of "having high scores but poor ability" is only one expression caused by the lack of humanistic spirit for the 20th century students, the phenomenon of "knowledge, no culture” is more serious[4]. In 2011, Jiangxi province carried out the first event about "Survey of Jiangxi Province Public Humanities and Social Science Literacy", and published an investigation report[5]. The report shows that, although people thought to enhance the humanistic quality had a significant meaning, but the test results about the basis human knowledge is a bit worrying, Taoism and Confucianism in China has more than two thousand years, but the people actually accepted the test, $27.1 \%$ consider LAOZI was a representative figure of Confucian, $4.2 \%$ consider LAOZI is a representative figure of the Legalists, and another $4.2 \%$ choose "I Do not know".

If anybody think about the case of Ma Jiajue who become to a campus butcher from a merit student in 2004, Fu Chengli who become a violent killers from a unshine boy in 2008, Yao Jiaxin who changed to a "cruel murderer" from "God's favored one" in 2010, and recently the killing teacher case occurred in Jiangsu university of science and technology, and other unreasonable and irrational things like "World of Warcraft Trading", abortions of female college students and so on demonstrated that people do not know Taoism representative figure is not just the lack of cultural knowledge, but the higher education longterm lack of humanistic spirit is terrible. The root cause of this situation is caused by higher education long-term exercise a high degree of differentiation of specialized education, and this is concentrated expression of humanism and literacy artificially separated.

\section{Universities Urgently Need the Unity Education of Human Spirit and Science Literacy}

The history and reality of human society education has proven that humanities should have valuable natural science, the decline of the humanities today show that the humanities without natural science is incomplete; however, natural science without human spirits is also incomplete, even dangerous, drug professors' case is a typical crime case that use the professional knowledge, and endless stream of suicide, homicide, killing teacher and matricide happened in the universities force us to ponder, what makes the students, even scholars accepted higher education, disregard life like that? This is not just the life education topic about fear and respect life, take responsibility, improve the resistance to the life frustration[1], but are closely related to the absence of humanistic education in modern higher education, colleges and universities urgently need the unity of human spirits and science literacy.

\section{Integrate Humanities and Science, Implement Science \& Humanity Education}

\section{The Connotation of Science \& Humanity Higher Education}

Science and humanity had great contribution to society progress and personal liberation, but because of the narrowness of humanistic spirit and the utilitarian of science \& technology, humanities is helpless when it face science and technology. Today, science and technology is developed rapidly, but it is more and more apparent that this decelopment can bring disaster to mankind, in order to avoid the human destruction, people must control this development, making it with a human face, and let it service for humanity, this is to make science and humanity adapt to the development of times and technology requirements.

Science and humanity not only believe science, but also advocate the humanity, where science and technology as a basic mean, the humanistic spirit as the value of the objectives, the purpose is to promote the harmonious development of natural science and human spirit. Science and humanity not only concern the humanity in science and technology, but also pay attention to the scientific value of the humanistic spirit, in the field of science and humanity education, natural science is the foundation, humanistic value is the objective, development of natural sciences and the human spirit is coordinated, and complement each other, real service for the human life.

Therefore, higher education with science and culture should combine the core of the human spirit and the natural sciences, it should based on natural science, oriented by humanistic spirit, focus on the personality development, and emphasis a blend of science \& humanity in professional development, reshape the individual and coordinate the role of social through education, to promote educational innovation through the science research, and highlight the humanity through science and humanities, therefore, the concept of science and humanity education fully reflect the human values and imbued with a strong sciences and humanities spirit.

\section{Objective of Science \& Humanity Higher Education}

In 21st century, human society is facing four trouble, they are all life will be eliminated by the nuclear war on Earth; whether mankind can survive from the ecological destruction for continuous development of industrialization; population growth and the North-South confrontation is likely to cause global conflict, structural unemployment as a result of the rapid expansion by production automation. Education in 21st century must cultivate the ability to resolve these challenges.

United Nations experts in education, S. Rasskh and G. Vaideanu, noted, "We do not forget that the beneficial effect of the 
philosophy of the Renaissance and Enlightenment period in the transformation of education, in particular, should keep in mind the precious example of ancient Greece. As Karl Marx pointed out, in ancient Greece, an ideal objective as a strong and lasting yearning physically and spiritually successful in shaping the human. In any case, educational activities and educational institutions only follow one of the highest purpose only reason to exist"[6]. The ultimate goal is to "perfect personality" by integrate science and humanity education.

\section{The Realization of Science \& Humanity Higher Education}

Artificial fragmentation of science literacy and humanism spirit education is biased, some people is increasingly inclined to the coordinated development of the human spirit and science literacy, practice to carry out an active exploration and research, and achieved significant results[7,8].

1) Establish the education methodology for science and humanity education. Research of educational theory started in the 1920 s, in the development process, it is bound by the semicolonial and semi-feudal society for a long time, therefore, the theoretical development has been in a state of brief introduction and imitation for the foreign theory, the main content was the study of educational theory in the United States and Japan. After the founding of new China, due to the impact of political factors, since the 1950s, higher education in China began to learn, even copy the Soviet Union education theory, but in the 1980 s, once again study western educational theory, all of these indicate that our educational theory lack of self-consciousness and subjective consciousness, and our own educational theory has not well established.

After the reform and opening up, Deng Xiaoping proposed that education objective should be face modernization, face the world and face future, China's education once again on track; In the 1990s, Jiang Zemin proposed that education should achieve "two important changes", he pointed out that the education necessary to change the development way from extension and expansion to the connotation elevation, and pay close attention to the quality of education; Change the low efficiency classroom but increase burden outside classroom to improve high efficiency classroom but decrease burden outside classroom, create effective classroom, "China Reform and development Outline" and "facing 21st century China Education Revitalization Action plan" has promulgated since 1993, the outline and the plane pointed out the direction to improve the quality of education, and set forth requirements for the development of China's educational theory, also brought the opportunity to develop by leaps and bounds.

In human society start the second decade of the 21st century, people should summarize the results of education in China since the reform and opening up, establish education methodology with a connotation of science and humanities, provide strong support for Chinese education.

2) Build combination of science and humanity education from the two history. In history, the main content of Chinese education is traditional humanity education and the education content is Confucianism. Science literacy education was gradually rise up after the Western education system was introduced into China, the concept and definition of the word "SCIENCE" gradually clear after the argumentation such as China's knowledge is the fundament and the western learning to use, it can be said that modern Chinese education from a humanisty education to science education was directed by the value of the science literacy education, therefore, there is superiority in the field of the combination of science literacy and humanism spirit in China. But the education system did not coordinate the relationship of humanism spirits and science literacy, especially since the Opium War, "Behind will be beaten" deeply rooted in it, exaggerated the role of science, but negated human spirit, these cause the serious deficiencies of the human spirit in today higher education.

Higher education should summarize the education history of humanities and science, it is necessary to strengthen the scientific knowledge, and promote the scientific literacy.

3) Establish new order of science and humanity education. There are some significant problem in modern Chinese higher education, mainly reflected as the five field: the first is higher education has been divided into liberal arts and science, and the classification began to adopt from secondary school, there is almost no communication among various subjects; The second is the course settings cared more is the professional features, rarely take into account the role of the humanistic spirit in professional training; The third is emphasis on the professional knowledge too much, makes students' disciplinary perspective and academic atmosphere has been greatly restricted. The fourth is the impact of various trades and industries emphasize economic construction in recent years, the utilitarian invade the education system; The fifth is no matter what kind of students, the same teaching programs and the same curriculum was used in the school education, which affect students' overall quality training and suppress students' personality development.

All of these questions show that university education quality and efficiency can not match the times requirements, it need to find and establish new educational order which based on the science and technology, oriented by the humanistic spirit.

\section{The Implement of Science \& Humanity Higher Education}

1) Set general courses for science literacy \& humanistic spirit. Based on these ideas, university should set up some general courses, such courses should include humanity, social science and natural science, such as science and technology philosophy, basic science, astronomy, geography, aesthetics, psychology, art, history, economics and so on; such courses teaching, on the one hand, emphasize on ethics and responsibility, respect for personal believes and cultures, on the other hand to highlight the human spirit and scientific literacy to help students to establish a correct world outlook, values and aesthetics, while focusing on students correct view of science and rational wisdom. In addition, the general courses should pay attention to inspire, enlighten and infected students, the pursuit of macro knowledge and vast nature, giving prominence to improve the educational goals of personality.

Set up general courses could not just focus on professional courses, it need to emphasize the integration of the human spirit and scientific literacy, the courses need to connect with the life, 
and have a strong science, humanities and openness, they are able to accommodate the development in all aspects of the students. Based on these, the author opened a general course of "physical thinking and humanistic spirit" in NUIST, the course tried to introduce the human spirit in the process of physics development but not to appear formula, the course examination was mainly in the form of attendance and course paper, the teaching effectiveness is very good.

2) Create a campus culture for scientific literacy and the human spirit education. The spirit of the students humanities is to rely on the development, practice has proved that construct a variety of campus culture with strong humanistic atmosphere is an effective way to cultivate the humanistic spirit of college students. To create a campus culture, on the one hand should to organize series lecture that is conducive to improving the scientific quality, create a free academic atmosphere that without the pressure of examinations, therefore, the speaker gives such talks need to take a meticulous planning, not only the topic has a distinctive theme, but also the speak has the passion during the speech, so as to producing the effect of human spirit; On the other hand, the University should regularly organizes cultural festivals, science and technology festival, cultural salons, book clubs, film and television reviews, poet friends and other such activities in the campus, and advocate the students participate in various activities, by this way, let the students feelings to be sublimated in the college campus, and let the students' sense of responsibility, sense of mission, sense of obligation and dedication to be strengthened from these activities. Third, colleges and universities as talent training base should increase funds input, improve the teaching conditions, updated laboratory equipments and supplement library resources, at the same time, colleges and universities should strengthen the campus landscape construction and create cultural landscape in campus, so that students both in first-class laboratory with advanced equipment, early exposure to advanced science and technology to improve the scientific quality, but also thought provoking, cultivate character and sublimate the spirit in a beautiful campus environment.

In May 2012, NUIST organized the international students from and hold the first International Cultural Communication Festival, the activities conducted only one morning, but it has played a positive significance for the communication of Chinese stedents and the international students, and it also played a positive meaning of the promotion of Chinese students understand the culture of other Third World countries.

3) Implement teaching reform of science education combine humanity and humanity education combine science. On the basis of carring forward the fine traditions of the humanities, it should restraint the radical voluntarism and extreme romanticism in the humanities, and fully integrate into the scientific thinking, such as inject logical spirit, enter the scientific world outlook and respect for the rules of nature science laws, let science promote the progress of humanities education and discipline self-improvement, make it as an important symbol of liberal arts education endeavour. Apart from these, liberal arts education also needs to draw on the scientific method, such as scientific empirical reasoning, and the critique, innovation and enterprising based on scientific method. Some specific content of science education is abstracted and decomposed by science liberal arts education, and this content is integrated into the humanities education and research with the use of scientific creativity, reasoning and critical, so that liberal arts students obviously feel the appeal of science in their own professional, and to understand the compatibility between science and liberal arts education. By this integration of science and liberal arts education reform, it can can remedy the pragmatic awareness and utilitarian mentality of the traditional liberal arts.

By the way of setting general courses, NUIST has done a lot of work for the combination of science and humanity education in recent years, the school set "College Language" as a general course, and every science and engineering students must elective it; according to the school in advantage of the atmospheric sciences, require all discipline set up two "meteorological characteristics" courses as the must elective courses. In addition, the science and engineering students must select a "humanism" kind course and all liberal arts students are asked to select a "Science Literacy" kind course during the college, there are over 60 general courses for students to select every semester, the general courses involved in history, arts, literature, philosophy, science, engineering, agronomy, medical, business, management science and other various disciplines, this kind of course set up can promote the integration of students' scientific literacy and humanistic spirit, it play a positive role of right extend the students' cause.

\section{Conclusions}

Improve the Science Literacy of liberal arts students and the humanistic spirit of science students, the integration of the humanistic spirit and science literacy is becoming a consensus. The combination of science literacy and humanistic spirit in higher education based on the science education, oriented by the humanistic spirit, it is performance as infiltration of science and humanities, it stress the unity of the moral, sciences and humanities, the ultimate aim is to shape a complete personality.

\section{REFERENCES}

Zheng Xiaojiang, Luo Jialu, Life worry and think[M], Fu Zhou: Fujian Education Press, 2012.1.

Yang Haibo, Study on Connotation and Cultivation of Humane Spirit[J], Journal of Changchun University of Science and Tech-nology (Higher Education Edition), 2008, 3(3), P115-118.

Wang Xuenan, Ye Baosheng, The dimensions of scientific liter-acy study on three-dimensional goal of science education in China inspiration[J], Journal of Capital normal university (Natural sci-ence edition), 2012, 32(1), P60-64.

Mu Yi, Peng Lin, Knowledge no culture worry, Interview with the College of Humanities, Tsinghua University professor of his-tory Peng Lin, Xiao Kang[J], 2006, (7), P30-33.

Zhu Huanghe, Huang Wanlin, Ma Xuesong, Long Henan, Xie Xiaowei, Yi Waigen, Cao Cairong, Zhao Huawei, Jiangxi Provin-cial Public Humanities and Social Science literacy and needs sur-vey [J], Journal of Social Work, 2011, (10), P58-62.

S. Rasskh, G. Vaideanu, Global outlook from now to 2000 educa-tional content development[M], Ma Shengli, Beijing: Education and Science Press, 1992。

Li Guiyou, On the scientific and humanistic education[J], The world 
S. X. PEI ET AL.

and Chongqing, 2010, 27(12), P79-81.

Mao Yalong, Higher education of scientific humanism[J], Journal of architectural education in institutions of higher learning, 2011, 20(4), P1-5. 